\title{
INTERPRETIVE SUMMARIES, OCTOBER 2015
}

Invited review: Inflammation during the transition to lactation: New adventures with an old flame. By Bradford et al., page 6631. In the past decade, a wide variety of studies have clearly demonstrated that most dairy cows experience some degree of systemic inflammation during the transition to lactation. Higher circulating concentrations of inflammatory markers have been associated with poor health and productivity outcomes, and controlled studies have shown negative effects of administering inflammatory mediators. Some positive responses to anti-inflammatory treatment during this window of time have been reported, but many other studies have failed to observe any effects. Although many questions remain, inflammation is emerging as an important signaling process affecting systemic physiology during the transition to lactation.

http://dx.doi.org/10.3168/jds.2015-9683.

Screening of Lactobacillus strains for their ability to produce conjugated linoleic acid in milk and to adhere to the intestinal tract. By SosaCastañeda et al., page 6651. This study demonstrated that 4 specific strains of Lactobacillus produced conjugated linoleic acid (CLA) in milk and under simulated gastrointestinal conditions. Also, these bacteria were able to adhere to the intestinal wall. Thus, these strains may be able to produce CLA in the gastrointestinal tract. To the best of our knowledge, this is the first time that CLA-producing strains have been selected based not only on CLA production in fermented dairy products but also on CLA production under simulated gastrointestinal conditions. Milk fermented by these specific Lactobacillus strains could be used as a functional food because it may confer the health benefits attributed to CLA.

http://dx.doi.org/10.3168/jds.2014-8515.

Evaluation of the efficiency of analytical assays to detect aflatoxin $M_{1}$ in milk from selected areas in Egypt and South Africa. By Mwanza et al., page 6660. Several methods and testing kits are proposed to analyse aflatoxin $\mathrm{M}_{1}\left(\mathrm{AFM}_{1}\right)$ in milk. This study aimed to evaluate 2 methods-ELISA and rapid $\mathrm{AFM}_{1}$ immunochromatographic strip test-compared with the conventional methods thin layer chromatography (TLC) and high-performance liquid chromatography (HPLC). One hundred thirty-eight milk samples from Egypt and South Africa were analyzed. South African ELISA results showed satisfactory correlation with HPLC reults. Eighteen $(20.45 \%)$ of the Egyptian samples positive by ELISA had levels of $\mathrm{AFM}_{1}$ above the European Union regulatory limit $(50 \mathrm{ng} / \mathrm{L})$, whereas 65 samples $(73.9 \%)$ were above the Egyptian regulatory limit $(0 \mathrm{ng} / \mathrm{L})$. We recommend combining a screening test (immunochromatographic strip, TLC, or both) with a confirmatory test such as HPLC to ensure milk with low or absent levels of aflatoxins to ensure consumer safety.

http://dx.doi.org/10.3168/jds.2014-9220.

Amaltheys: A fluorescence-based analyzer to assess cheese milk denatured whey proteins. By Lacotte et al., page 6668. This article introduces a fluorescence-based Amaltheys analyzer (Spectralys Innovation, Romainville, France) to measure protein fractions in milk and other dairy products. The analyzer measures the natural fluorescence of tryptophan, an aromatic amino acid present in most proteins. Following specific sample preparation, tryptophan fluorescence can be used to calculate the content of a protein family in dairy products. Such proteins present many technological and functional properties and play an important role in cheese yield and quality. The performance of Amaltheys measurements is described, followed by a 4-mo industrial trial to demonstrate its ability as a rapid process-monitoring tool.

http://dx.doi.org/10.3168/jds.2015-9412.

Quality characteristics and plasmin activity of thermosonicated skim milk and cream. By Vijayakumar et al., page 6678. The shelf life of hightemperature, short-time (HTST) pasteurized milk is approximately $21 \mathrm{~d}$. Heat-stable proteases not denatured during pasteurization can reduce milk shelf life by hydrolyzing proteins and causing gelation or coagulation. Although the use of higher temperatures or holding times compared with standard HTST pasteurization conditions can denature proteases, such conditions can produce off-flavors in milk. In this work, we evaluated a new processing option, based on high power ultrasonics, for its potential in extending the enzymatic, aroma quality, and microbial shelf life of fluid milk. Ultrasound reduced or inactivated food spoilage enzymes (plasmin system) and microorganisms without detrimentally affecting aroma, and thus holds potential for extending the shelf life of milk.

http://dx.doi.org/10.3168/jds.2015-9429.

Formation of volatile compounds in kefir made of goat and sheep milk with high polyunsaturated fatty acid content. By Cais-Sokolińska et al., page 6692. We investigated volatile compounds in kefir from goat and sheep milks with high polyunsaturated fatty acids (PUFA) content as a result of feeding animals with forage supplemented with maize dried distillers grains with solubles (DDGS). The content of PUFA had a significant influence on the aroma profile of the 
resulting kefirs. An increase in the content of PUFA resulted in loss of the whey aroma in goat milk kefirs and of the animal odor in sheep milk kefirs. http://dx.doi.org/10.3168/jds.2015-9441.

Improvement of skin condition by oral supplementation with sphingomyelin-containing milk phospholipids in a double-blind, placebo-controlled, randomized trial. By Higurashi et al., page 6706. Milk is a convenient dietary source of sphingomyelin, which is a key epidermal phospholipid. We investigated the effect of supplementation with a milk-derived phospholipid concentrate containing sphingomyelin on the condition of skin in healthy adults with low skin hydration. Supplementation with the concentrate daily for 12 wk significantly improved heel skin hydration, eye skin elasticity, and subject-reported facial moisture and wrinkling. These results indicate that dietary sphingomyelin can improve the general condition of skin.

http://dx.doi.org/10.3168/jds.2015-9529.

Visible and near-infrared bulk optical properties of raw milk. By Aernouts et al., page 6727. The quality of milk is important for the dairy farmer, milk processing plants, retail and the consumer. Optical techniques based on visible/near-infrared spectroscopy (Vis/NIR) have already proven their potential for automated monitoring of the milk composition and microstructure, as these properties are related to the absorption and scattering, respectively, of light. Nevertheless, the interaction between absorption and scattering of the light travelling through the sample complicates the interpretation of the measured signals. Therefore, the sensor should be well designed and combined with a robust light propagation model to obtain accurate predictions of the milk properties. In this paper, the Vis/NIR bulk optical properties of raw milk were studied and reported. This information is essential for the optimization of a Vis/NIR optical milk quality sensor. http://dx.doi.org/10.3168/jds.2015-9630.

Resource recovery using whey permeate to cultivate Phellinus linteus mycelium: Solid-state and submerged liquid fermentation. By Cho et al., page 6739. Whey permeate can be bioconverted to Phellinus linteus mycelium, thereby simultaneously reducing organic wastes and producing highly valuable products. This bioconversion process can be performed using either solid-state fermentation (SSF) or submerged liquid fermentation (SLF). In this study, the optimum growth conditions and significant engineering factors to cultivate $P$. linteus mycelium using whey permeate as a sole substrate were evaluated in SSF and SLF systems. This research will contribute to establishment of an economically beneficial bioconver- sion process for mass production of $P$. linteus mycelium using whey permeate.

http://dx.doi.org/10.3168/jds.2015-9631.

In vitro and in vivo examination of anticolonization of pathogens by Lactobacillus paracasei FJ861111.1. By Deng et al., page 6759. Pathogenic infections normally shape the gut microbiota from "balance" to "imbalance" status. Modulation of gut microbiota by probiotics in the host following pathogenic infection is not well studied. Milk-derived Lactobacillus paracasei FJ861111.1, which showed good probiotic characteristics in vitro, was able to exclude pathogens from the gut of the host after infection and generate a more diverse microbiota during the consumption of this probiotic organism. This strain could be a good candidate for a probiotic for producing functional milk products.

http://dx.doi.org/10.3168/jds.2015-9761.

Enzymatic production of lactulose and epilactose in milk. By Rentschler et al., page 6767. Production of lactulose and epilactose in milk was examined by application of the cellobiose 2-epimerase from Caldicellulosiruptor saccharolyticus. The thermophilic enzyme was utilized at $50^{\circ} \mathrm{C}$ and $8^{\circ} \mathrm{C}$, a process-relevant temperature for milk processing. To the best of our knowledge, this is the first time that an enzyme has produced lactulose directly in milk in situ. The results show the potential of one enzyme to enhance the value of milk sugar in a complex food matrix at both high and low temperatures.

http://dx.doi.org/10.3168/jds.2015-9900.

Effect of $\beta$-hydroxybutyric acid, parity, and body condition score on phenotype and proliferative capacity of colostral mononuclear leukocytes of high-yielding dairy cows. By Meganck et al., page 6782. Colostrum and health status of calves cannot be separated from each other. In addition to maternal antibodies, colostral leukocytes are absorbed by the calf's gut. The functional importance of these cells is not yet fully understood and few articles describe factors affecting phenotype or activation state of bovine colostral lymphocytes. In the present study, parity had a significant effect on mitogen- and antigen-induced proliferation of colostral cells. Also, body condition of cows and their $\beta$-hydroxybutyric acid serum concentration significantly affected the percentage of colostral B- and T-lymphocytes and macrophages. http://dx.doi.org/10.3168/jds.2014-8780.

Evaluation of the Johne's disease risk assessment and management plan on dairy farms in Ontario, Canada. By Pieper et al., page 6792. The Ontario dairy industry launched a Johne's disease 
control program between 2010 and 2013. The objective of this study was to evaluate the risk assessment and management plan used in the program. Some of the management factors evaluated in the risk assessment predict the herd-level or within-herd prevalence. Farms with high risk scores in any management area were more likely to receive management recommendations for those areas. Overall, the risk assessment is a useful tool to identify risk factors for Johne's disease on Ontario dairy farms and to determine recommendations for Johne's disease control.

http://dx.doi.org/10.3168/jds.2014-8813.

Animal health and welfare planning improves udder health and cleanliness but not leg health in Austrian dairy herds. By Tremetsberger et al., page 6801. Animal health and welfare planning is a structured process for improving health and welfare of farm animals. We assessed 34 Austrian dairy farms, and farm-specific improvement measures were developed jointly with the farmers in a participatory approach. The average implementation rate of $57 \%$ was similar to or higher than that of other studies. Interventions improved udder health and cleanliness after $1 \mathrm{yr}$, but did not improve leg health. Human-animal relationship and agonistic social behavior were already at a satisfactory level and thus were rarely addressed. The structured, participatory process of animal health and welfare planning appears to be a promising way to improve at least some animal health and welfare issues. http://dx.doi.org/10.3168/jds.2014-9084.

Characterization of peripartum rumination and activity of cows diagnosed with metabolic and uterine diseases. By Liboreiro et al., page 6812. Technologies to monitor rumination and activity of cows are available and accessible to dairy producers and may facilitate and expedite disease diagnosis. Prepartum rumination was reduced among cows delivering stillborn calves and among cows diagnosed with subclinical hypocalcemia and retained fetal membranes. Postpartum rumination was reduced among cows delivering twins. In the first week postpartum, rumination was reduced among cows diagnosed with subclinical hypocalcemia, retained fetal membranes, and subclinical ketosis. Prepartum activity was reduced among cows delivering twins and increased among cows delivering stillborn calves. More experiments are necessary to determine how the rumination and activity data may be used for early diagnosis of postpartum diseases.

http://dx.doi.org/10.3168/jds.2014-8947.

Genomic characteristics of Staphylococcus aureus strains associated with high within-herd prevalence of intramammary infections in dairy cows. By Cremonesi et al., page 6828. This paper describes the genotyping of Staphylococcus aureus isolated from 16 dairy cattle herds classified by the prevalence of different intramammary infections. All were genotyped using a method based on the amplification of the 16S$23 \mathrm{~S}$ ribosomal RNA intergenic spacer region. Between the isolates, 54 selected strains were also genotyped with multi-locus sequence typing, spa (staphylococcal protein A) typing, ribotyping, pulssed-field gel electrophoresis, and multiplex polymerase chain reaction. Different molecular approaches were applied in order to identify specific molecular characteristics associated with strains of pathogenicity and infectivity. http://dx.doi.org/10.3168/jds.2014-9074.

Feed intake is related to changes in plasma nonesterified fatty acid concentration and hepatic acetyl CoA content following feeding in lactating dairy cows. By Piantoni et al., page 6839. This study evaluated the relationship between dry matter intake during the first $4 \mathrm{~h}$ after feeding and hepatic acetyl CoA (AcCoA) content in postpartum and late-lactation dairy cows. Hepatic AcCoA content and plasma nonesterified fatty acids (NEFA), $\beta$-hydroxybutyrate, glucose, and insulin concentrations were evaluated before and $4 \mathrm{~h}$ after feeding. Results indicate that a reduction in plasma NEFA concentration was associated with a decrease in hepatic AcCoA content and greater dry matter intake at $4 \mathrm{~h}$ after feeding in both postpartum and late-lactation cows, consistent with the hepatic oxidation theory of the control of feed intake. However, the reduction in AcCoA during feeding was related to the reduction in plasma NEFA concentration for postpartum cows only.

http://dx.doi.org/10.3618/jds.2014-9085.

Determination of optimal diagnostic criteria for purulent vaginal discharge and cytological endometritis in dairy cows. By Denis-Robichaud and Dubuc, page 6848. Vaginal discharge scoring was used to diagnose purulent vaginal discharge, whereas endometrial cytology and leukocyte esterase testing were used to diagnose cytological endometritis. Both forms of reproductive tract disease were associated with a detrimental effect on subsequent reproduction. These study results suggest that the use of leukocyte esterase could be a good alternative to endometrial cytology. http://dx.doi.org/10.3168/jds.2014-9120.

Randomized clinical trial of intrauterine cephapirin infusion in dairy cows for the treatment of purulent vaginal discharge and cytological endometritis. By Denis-Robichaud and Dubuc, page 6856. The effect of intrauterine cephapirin infusion on reproductive performance of Holstein cows affected by reproductive tract disease was quantified. Overall, intrauterine cephapirin treatment increased the proportion of pregnant cows at first service by 9 to 16 percentage points. The effect of cephapirin treatment was of 
similar magnitude in cyclic cows but was reduced in anovular cows.

http://dx.doi.org/10.3168/jds.2014-9129.

Late-gestation heat stress abatement on performance and behavior of Holstein dairy cows. By Karimi et al., page 6865. The effect of cooling during the close-up period on feeding behavior and production performance of Holstein dairy cows was investigated. Feeding and chewing behavior were disturbed in heat-stressed versus cooled cows and thereby intake decreased. Cooling increased production of milk and milk components over the entire experimental period. Cooling during the close-up period should be implemented by dairy producers to reduce economic and welfare losses from heat stress.

http://dx.doi.org/10.3168/jds.2014-9281.

Effects of prepartum fat supplementation on plasma concentrations of glucagon-like peptide-1, peptide YY, adropin, insulin and leptin in periparturient dairy cows. By Zapata et al., page 6876. Supplementing fat prepartum appears to offset the deficits in energy balance postpartum; however, little is known of the underlying hormonal and metabolic adaptations. We evaluated the effects of prepartum dietary canola and sunflower seed supplementation on plasma concentrations of gut hormones and metabolites. We found that dietary lipid alone had no effect on energy balance, plasma hormone and metabolite concentrations. Importantly, transition from pregnancy to lactation increased plasma concentrations of glucagonlike peptide-1, peptide YY, adropin, nonesterified fatty acids, and $\beta$-hydroxybutyrate while decreasing insulin and leptin. In conclusion, physiologic state is a stronger determinant, than dietary lipid, of changes in hormones and metabolites in transition dairy cows.

http://dx.doi.org/10.3168/jds.2014-9283.

Application of the Welfare Quality protocol to dairy buffalo farms: Prevalence and reliability of selected measures. By De Rosa et al., page 6886 . Within the general aim of developing a Welfare Quality system for monitoring dairy buffalo welfare, we assessed the reliability of a number of variables to be directly measured on the animals. Most of the proposed measures can be reliably included in the final scheme, which could be used to monitor buffalo welfare after appropriate refinement. However, in order to identify and promote the application of the best farming practices, the welfare status of each farm should be benchmarked with that of a reference population.

http://dx.doi.org/10.3168/jds.2015-9350.

Differential expression of living mammary epithelial cell subpopulations in milk during lactation in dairy cows. By Baratta et al., page 6897. This study aimed to characterize the living epithelial cells present in milk of dairy cows and to identify mammary epithelial cell precursors by immunophenotypic characterisation during lactation. This research demonstrates a new methodological approach and investigates the presence of these cellular fractions that may be of interest. We hypothesize that specific epithelial subpopulations may play a role in mammary milk secretary function.

http://dx.doi.org/10.3168/jds.2015-9369.

Methods of estimating liner compression. By Leonardi et al., page 6905. Liner compression (LC) is the pressure applied to the teat end when the liner collapses during the rest phase (d-phase) of pulsation. Liners with higher LC are thought to increase the occurrence of teat-end hyperkeratosis. Overpressure has been proposed as a relative indicator of LC. The aim of this study was to compare 2 methods of measuring overpressure using a new test device. Overpressure was estimated for 6 different liners using the same population of 24 quarters of 6 cows. Overpressure values were also compared with LC estimates on the same liners made with a novel artificial teat sensor. The new test device had several advantages over previously published methods of measuring overpressure.

http://dx.doi.org/10.3168/jds.2015-9380.

Molecular epidemiology and strain-specific characteristics of Streptococcus agalactiae at the herd and cow level. By Mahmmod et al., page 6913. Many people carry Streptococcus agalactiae in their gastrointestinal and urogenital tracts. It has been suggested that people may act as source of infection for cattle. It has also been suggested that human strains of $S$. agalactiae do not affect cows in the same manner as bovine strains. We show that strains of $S$. agalactiae that may affect people as well as cattle are probably spread through cow-to-cow transmission and that subtle differences exist in the cow-level response they elicit. Many $S$. agalactiae-positive cows have somatic cell counts (SCC) below 200,000 cells/mL and may go undetected in an SCC-based screening program.

http://dx.doi.org/10.3168/jds.2015-9397.

Cooling cows efficiently with sprinklers: Physiological responses to water spray. By Chen et al., page 6925. Dairy cows are commonly cooled with sprinklers mounted over the feed bunk. These systems use potable water - an increasingly scarce resource-but there is little experimental evidence for the optimal amount to apply. We restrained lactating cows in headlocks for $1 \mathrm{~h}$ to evaluate 3 sprinkler flow rates $(0.4,1.3$, and $\geq 4.5 \mathrm{~L} / \mathrm{min}$ in four 3 -min applications) and an unsprayed control. The intermediate flow rate $(1.3 \mathrm{~L} /$ min) best balanced cooling effectiveness against water 
usage: after $1 \mathrm{~h}$, it reduced respiration rate and skin temperature relative to baseline and kept body temperature lowered for an additional $30 \mathrm{~min}$ after testing. http://dx.doi.org/10.3168/jds.2015-9434.

Diets rich in starch improve the efficiency of amino acids use by the mammary gland in lactating Jersey cows. By Cantalapiedra-Hijar et al., page 6939. It has been shown that at similar energy and $\mathrm{N}$ intakes, diets rich in starch increase milk $\mathrm{N}$ yield in dairy cows compared with diets rich in fiber. This study aimed at evaluating whether this higher efficiency of $\mathrm{N}$ utilization was the consequence of a better use of amino acids (AA) by the mammary gland. Our results showed that the mammary gland became more sensitive to the supply of AA when feeding starch compared with fiber diets, increasing the ability of the mammary gland to extract AA.

http://dx.doi.org/10.3168/jds.2015-9518.

Adipocyte differentiation-related protein promotes lipid accumulation in goat mammary epithelial cells. By Shi et al., page 6954. In nonruminants, adipocyte differentiation-related protein (ADRP; gene symbol PLIN2) is known to regulate cytosolic lipid droplet (CLD) synthesis. Using goat mammary epithelial cells (GMEC), this study demonstrated that the ADRP protein co-localizes with CLD. Oleic acid supplementation further enhanced its localization on CLD and intracellular lipid accumulation. Overexpression of $A D R P$ significantly increased intracellular lipid accumulation and concentration of triacylglycerol (TG), whereas knockdown of ADRP decreased both. Moreover, ADRP could rescue the decrease in CLD accumulation induced by adipose triglyceride lipase. Results suggest that ADRP is a key factor regulating CLD metabolism in goat mammary cells during lactation.

http://dx.doi.org/10.3168/jds.2015-9452.

An estimation of the clinical mastitis incidence per 100 cows per year based on routinely collected herd data. By Santman-Berends et al., page 6965. Two prediction models were developed on routinely collected herd data to (1) predict the clinical mastitis incidence (CMI) for all Dutch dairy farms, and (2) detect herds with a high CMI. From 227 Dutch dairy herds, all routinely collected data and prospectively collected data of clinical mastitis during 2013 were available. Based on routinely collected herd data, it was possible to accurately estimate the average CMI for all dairy herds and to correctly classify $77 \%$ of the herds with a high CMI. With the prediction models, it is possible to periodically monitor CMI both at the herd and national level.

http://dx.doi.org/10.3168/jds.2015-9642.
Prevalence of lameness and associated risk factors in Canadian Holstein-Friesian cows housed in freestall barns. By Solano et al., page 6978. The prevalence of lameness for dairy cows housed in 141 Canadian herds was $21 \%$, and prevalence was related to facility design, management practices, and individual cow variables. Lameness prevalence was higher in barns with very slippery flooring but lower in barns with sand or dirt stall base or with bedding $\geq 2 \mathrm{~cm}$ deep. Lameness increased as parity increased; furthermore, cows with low body condition, injured hocks, or overgrown claws were more often lame. In conclusion, improving management of multiparous, thin, or injured cows and improving the slip resistance of the floor and the stall's lying surface were expected to reduce the prevalence of lameness.

http://dx.doi.org/10.3168/jds.2015-9652.

Modeling of daily body weights and body weight changes of Nordic Red cows. By Mäntysaari and Mäntysaari, page 6992. Automated weighing systems yield large amounts of body weight (BW) data from dairy cows in a short time. The usefulness of the data depends on the reliability of the measures. If the measures are unbiased, the change in BW describes the energy status of the cow. The noise in BW measurements can be smoothed by fitting a parametric or time-series model into the BW measurements. This study examined 5 models for prediction of BW. All fitted models increased the reliability of the BW measurements; the best predictive value was found with a regression model having fixed and random animal lactation stage functions. Thus, modeling of BW significantly increases the usefulness of BW as an energy balance and management indicator

http://dx.doi.org/10.3168/jds.2015-9541.

Factors affecting expression of estrus measured by activity monitors and conception risk of lactating dairy cows. By Madureira et al., page 7003. Reproductive and productive factors on estrus expression and conception rate were analyzed. Preovulatory follicle diameter at estrus was not correlated with estrus intensity or duration, whereas parity, body condition and secondary signs of estrus significantly affected estrus measurements. Lower producing cows had higher estrus activity, but overall correlation with milk production was weak. High estrus intensity episodes translated into more pregnancies. Quantitative data from estrus expression might be used to survey and predict fertility measures in dairy cows.

http://dx.doi.org/10.3168/jds.2015-9672.

Associations between hepatic metabolism of propionate and palmitate in liver slices from transition dairy cows. By McCarthy et al., page 7015. Energetic demands for lactation nearly double 
energy requirements compared with those of the precalving period. One of the increases in energy needs is for making milk lactose, mostly via gluconeogenesis in the liver. This rapid increase in glucose demand for milk lactose synthesis requires a very careful orchestration of the utilization and interaction of fatty acids and propionate at the liver to supply energy to the cow. Overall, results from this study suggest that conditions that lead to impairments in hepatic fatty acid metabolism during the transition period are associated with impaired postcalving liver glucose synthesis.

http://dx.doi.org/10.3168/jds.2015-9695.

Bacterial species and their associations with acute and chronic mastitis in suckler ewes. By Smith et al., page 7025. We examined 24 milk samples and 33 abscesses from 16 udders, alongside milk samples from 14 ewes with acute mastitis in one gland, to compare the bacterial species present. In total, 37 species were isolated but these did not vary by disease state. Staphylococcus aureus was the most common species detected, and closely related strains of $S$. aureus were present across all clinical presentations. Our results suggest that the udders of ewes with chronic or acute mastitis could be reservoirs for onward transmission of $S$. aureus to susceptible ewes.

http://dx.doi.org/10.3168/jds.2015-9702.

Tocopherols and tocotrienols in serum and liver of dairy cows receiving conjugated linoleic acids or a control fat supplement during early lactation. By Sadri et al., page 7034. Vitamin E comprises 8 different compounds. The effects of conjugated linoleic acid (CLA) supplementation on the concentrations of these vitamin $\mathrm{E}$ forms in serum and liver during early lactation in dairy cows were studied. In both groups, serum concentrations of $\alpha$ - and $\gamma$-tocopherol and $\beta$ and $\delta$-tocotrienol increased from d 21 prepartum to $\mathrm{d}$ 21 postpartum and then remained unchanged. In the control group, $\alpha$-tocopherol transfer protein mRNA increased with days in milk, which may point to its involvement in the increase of serum $\alpha$-tocopherol postpartum. The concentrations of the vitamin $\mathrm{E}$ forms were not affected by the CLA supplement at the dosage used.

http://dx.doi.org/10.3168/jds.2015-9710.

The rapid increase of circulating adiponectin in neonatal calves depends on colostrum intake. $B y$ Kesser et al., page 7044. Three trials were conducted to characterize the adiponectin concentrations in neonatal calves that were fed with either colostrum or formula. In trial 1, after colostrum consumption, the serum adiponectin concentrations were substantially greater than the values before feeding. In trial 2, calves fed colostrum had consistently higher plasma adiponectin concentrations compared with formula-fed calves. In trial 3, plasma adiponectin concentrations tended to be lower in preterm compared with term calves. Colostrum intake is essential to elevate blood adiponectin in neonatal calves.

http://dx.doi.org/10.3168/jds.2015-9726.

Long-term trends of nitrogen and phosphorus mass balances on New York State dairy farms. By Cela et al., page 7052. This study reports the range of change in $\mathrm{N}$ and $\mathrm{P}$ mass balances of 27 farms over 6 or more years, provides practical examples of management changes made by dairy farmers that improved their farm nutrient mass balances over time, and identifies indicators that can predict areas for improvement in mass balances.

http://dx.doi.org/10.3168/jds.2015-9776.

Conjugated linoleic acid isomers strongly improve the redox status of bovine mammary epithelial cells (BME-UV1). By Basiricò et al., page 7071. This in vitro study demonstrated that trans10,cis-12 and cis-9,trans-11 conjugated linoleic acid (CLA) isomers have antioxidant activity, particularly the trans-10,cis-12 isomer, by developing a significant elevated redox status in bovine mammary cells. These isomers exert a protective action against oxidative stress because they are potent inducers of glutathione synthesis, a potent intracellular antioxidant, without lipoperoxidation. Based on data of the present study, supplementation of CLA isomers during transition period may be useful for reducing the incidence of oxidative stress and related diseases in early lactation. http://dx.doi.org/10.3168/jds.2015-9787.

Short communication: Characterizing metabolic and oxidant status of pastured dairy cows postpartum in an automatic milking system. By Elischer et al., page 7083. The periparturient period is a physiologically stressful time for cows. The changes in metabolic and oxidative stress profiles of dairy cows in a pasture-based automatic milking system dairy have not been explored. This case study is the first to describe these parameters. Results from this study show that, although responses were within expected ranges, periparturient multiparous cows responded differently than periparturient primiparous cows with respect to metabolic and oxidative measures during the postpartum period, suggesting different management strategies may need to be considered with primiparous and multiparous cows.

http://dx.doi.org/10.3168/jds.2014-8941.

Short communication: Streptococcus canis is able to establish a persistent udder infection in a dairy herd. By Król et al., page 7090. A 15-month observation of a dairy herd has revealed that Streptococcus canis, a microorganism normally colonizing 
body surfaces of cats and dogs, is capable of causing long-term, subclinical udder infections in cows. Because the pathogen is likely to become highly adapted to udder tissue, control of the infection at the herd level may require similar measures to those adopted in Streptococcus agalactiae eradication programs. The study is intended to draw attention to Strep. canis as an important, emerging udder pathogen.

http://dx.doi.org/10.3168/jds.2015-9454.

Short communication: The effects of cabergoline administration at dry-off of lactating cows on udder engorgement, milk leakages, and lying behavior. By Bach et al., page 7097. The continuous increase in milk production in dairy cattle typically leads to high milk production at dry-off. A potential method to facilitate dry-off would consist of inducing direct cessation of milk production by interfering with hormonal signals. Cabergoline is an ergot derivative with high affinity for the $\mathrm{D}_{2}$ dopamine receptors that cause inhibition of prolactin secretion. Administration of cabergoline at dry-off resulted in a reduction in udder engorgement during the first day after dry-off, a reduction in milk leakage during the first $2 \mathrm{~d}$ after dryoff, and an increase in lying time of about additional $90 \mathrm{~min} / \mathrm{d}$ during the first day after dry-off compared with placebo.

http://dx.doi.org/10.3168/jds.2015-9751.

Hepatic metabolic response of Holstein cows in early and mid lactation is altered by nutrient supply and lipopolysaccharide in vitro. $B y$ Garcia et al., page 7102. Hepatic metabolism during the inflammatory response is poorly understood. This study used $\left[{ }^{13} \mathrm{C}_{3}\right]$ pyruvate to characterize the flux of intermediates involved in energy metabolism and the activity of enzymes that synthesize glucose. Inflammatory response to lipopolysaccharide altered the liver's ability to synthesize glucose for lactating dairy cows in vitro. Propionate and amino acids were used to replenish intermediates involved in energy metabolism but propionate was the preferred glucose-synthesizing substrate in the liver. Our results indicate that the synthesis of glucose in the liver is altered during inflammation and this response is independent of stage of lactation. http://dx.doi.org/10.3168/jds.2014-9034.

Effects of energy density in close-up diets and postpartum supplementation of extruded fullfat soybean on lactation performance, and metabolic and hormonal status of dairy cows. $B y$ Zhang et al., page 7115. The transition from late gestation to early lactation is the most challenging period for dairy cows, and it is often accompanied by negative energy balance and metabolic disorders. The importance of postpartum nutrition to support lactation cannot be overemphasized; moreover, prepartum feeding strate- gies impose dramatic effects on postpartum health and performance of cows. This study showed that restricting energy intake prepartum to prevent overconditioning at parturition had positive carryover effects on metabolism and production during early lactation. Postpartum supplementation of extruded full-fat soybean promoted milk production regardless of prepartum feeding level and improved postpartum health for cows that were overfed prepartum. http://dx.doi.org/10.3168/jds.2014-9112.

Rumen fermentation, blood metabolites, and growth performance of calves during transition from liquid to solid feed: Effects of dietary level and particle size of alfalfa hay. By Nemati et al., page 7131. Introducing forage in dairy calf diets during the milk-feeding period stimulates development of rumen musculature and maintains the integrity and health of the rumen wall. Particle size clearly affects rumen environment in young calves; however, further research is required to understand the effects of forage source, particle size, and their interaction with starter diets on rumen development and calf performance. http://dx.doi.org/10.3168/jds.2014-9144.

Energy content of reduced-fat dried distillers grains with solubles for lactating dairy cows. By Foth et al., page 7142. Fifty-six energy balances were completed with Holstein and Jersey multiparous cows in a study designed to determine the energy content of reduced-fat dried distillers grains with solubles through the use of indirect calorimetry. Two diets were tested which contained either 0.0 or $28.8 \%$ of reduced-fat dried distillers grains. Cows consuming these treatments produced similar amounts of milk but those consuming reduced-fat dried distillers grains with solubles produced milk with less protein. The concentration of net energy used for lactation was also higher in diets containing reduced-fat dried distillers grains with solubles.

http://dx.doi.org/10.3168/jds.2014-9226.

Colostrum quality affects immune system establishment and intestinal development of neonatal calves. By Yang et al., page 7153. The first meal of a neonatal calf after birth is crucial for survival and health. Three types of milk were used to determine the passive transfer of immunoglobulin G, immune and antioxidant status, intestinal morphology, and histology in neonatal calves. Calves that received high quality colostrum had a faster establishment of the immune defense mechanism and healthier intestinal environment. http://dx.doi.org/10.3168/jds.2014-9238.

Effects of precalving body condition score and prepartum feeding level on production, reproduction, and health parameters in pasture-based transition dairy cows. By Roche et al., page 7164. 
An experiment was undertaken to determine if grazing cows differing in body condition score a month before calving required different nutritional management. Results indicated that cows consuming $75 \%$ of their energy requirements before calving had a less severe negative energy balance after calving and a reduced risk of milk fever, irrespective of calving condition. However, immune competence was compromised in thin cows that were underfed before calving, possibly increasing the risk of infectious diseases. Cows in optimum condition or excessively fat will likely benefit from a 10 to $20 \%$ restriction in energy intake before calving, whereas thinner cows need to be fed to requirements.

http://dx.doi.org/10.3168/jds.2014-9269.

Effects of replacing wild rye, corn silage, or corn grain with $\mathrm{CaO}$-treated corn stover and dried distillers grains with solubles in lactating cow diets on performance, digestibility, and profitability. By Shi et al., page 7183. The price of corn grain, soybean meal, and high quality forages has risen to record high levels in China. Results from this study showed that including $\mathrm{CaO}$-treated corn stover and distillers grains with soluble as substitutes for expensive feedstuffs in diets can improve income over feed cost without negatively affecting the lactation performance of dairy cows.

http://dx.doi.org/10.3168/jds.2014-9273.

Parameterization of a ruminant model of phosphorus digestion and metabolism. By Feng et al., page 7194. Phosphorus (P) contamination of surface water can cause eutrophication, with negative impacts on aquatic life. Greater knowledge of the fate of dietary $\mathrm{P}$ and its utilization in the digestive tract would improve our ability to optimize $\mathrm{P}$ feeding and reduce $\mathrm{P}$ runoff. We revised and parameterized the Hill et al. (2008; J. Dairy Sci. 91:2021-2032) model using data from 6 studies. The revised model predicts that $94.6 \%$ of phytate and $57.8 \%$ of nonphytate, organic $\mathrm{P}$ are converted to inorganic $\mathrm{P}$, and $86.6 \%$ of inorganic $\mathrm{P}$ entering the small intestine is absorbed from the digestive tract. http://dx.doi.org/10.3168/jds.2014-9278.

Effect of dietary energy source and level on nutrient digestibility, rumen microbial protein synthesis, and milk performance in lactating dairy cows. By Zhou et al., page 7209. As the dairy industry has expanded, dairy cow production in China has rapidly increased. However, many types of alternative forage are not being fully utilized as animal feeds. Corn stover as a feed source contains lower level of nonfiber carbohydrates and fewer readily fermentable carbohydrates than high-quality forage grass, making it an inadequate energy source for the synthesis of rumen microbial protein, a factor that often results in decreased milk production. The results presented here suggest that an increased dietary energy level and ruminal degradation rate are beneficial to milk protein production when cows are fed corn stover as a forage source. We propose that this may be attributed to the increased supply of microbial protein.

http://dx.doi.org/10.3168/jds.2015-9312.

Inclusion of various amounts of steam-flaked soybeans in lactating dairy cattle diets. By Bruns et al., page 7218. Heat treating soybeans has been shown to lead to increased ruminal escape protein, which is required by high-producing dairy cattle. Many feedstuffs have been evaluated, however, there is a lack of research regarding steam-flaked soybeans. A feeding trial was used to evaluate the milk production effects of feeding steam-flaked soybeans in place of other heattreated soybean feedstuffs and fat supplements. Milk production and composition were similar with all diets. http://dx.doi.org/10.3168/jds.2015-9381.

The influence of age and weaning on permeability of the gastrointestinal tract in Holstein bull calves. By Wood et al., page 7226. The lining of the gastrointestinal tract functions to facilitate nutrient absorption while preventing the passage of potential harmful organisms and compounds. Weaning imposes dramatic shifts in the structure and function of the gastrointestinal tract and, correspondingly, is a critical phase for calves. The objective of this study was to assess the effect of age and weaning on permeability of the gastrointestinal tract in Holstein calves before and immediately following weaning. The data from this study suggest that permeability of the gastrointestinal tract decreases with age but weaning can disrupt this process and may increase permeability.

http://dx.doi.org/10.3168/jds.2015-9393.

Feeding preferences and voluntary feed intake of dairy cows: Effect of conservation and harvest time of birdsfoot trefoil and chicory. By Lombardi et al., page 7238. Bioactive forages may serve as natural alternatives to anthelmintics to maintain health and productivity in dairy cows. The objectives of this study were to quantify voluntary intake and preference of dairy cows for 2 bioactive forages: birdsfoot trefoil and chicory, harvested in the morning and evening, in addition to determining their time spent grazing on each forage species. Cows in the present experiments showed an overall preference towards baled forages compared with fresh forages, most notably toward birdsfoot trefoil baleage. Cow preference did not appear to be linked to harvest time (a.m. vs. p.m.).

http://dx.doi.org/10.3168/jds.2015-9427.

Differential rumination, intake, and enteric methane production of dairy cows in a pasturebased automatic milking system. By Watt et al., page 7248. We investigated linkages between rumina- 
tion time, intake, and enteric methane production of cows on pasture-based diets. Consistent differences in rumination and methane emissions were observed among high versus low ruminating animals. High rumination and methane was seen in older and heavier cows that had greater estimated dry matter intake and milk production. No independent effect of rumination time on enteric methane was detected. The dilution of enteric methane per unit of milk is confirmed as one alternative to reduce effects of biogenic methane emissions.

http://dx.doi.org/10.3168/jds.2015-9463.

Effects of partly replacing dietary starch with fiber and fat on milk production and energy partitioning. By Boerman et al., page 7264. We investigated the effects of 2 diets similar in energy content yet differing in starch, neutral detergent fiber, and fatty acids on milk production and energy partitioning in midlactation Holstein cattle. Intake was similar between treatments, with the high-fiber, high-fat diet reducing milk yield, milk protein concentration, and milk protein yield. The high-fiber, high-fat diet increased milk fat yield and concentration with a small improvement in milk:feed ratio (energy-corrected milk:dry matter intake). The high-fiber, high-fat diet partitioned fewer nutrients toward body reserves, as evident by reduced body weight gain, body condition score, and subcutaneous fat thickness, and partitioned more energy toward milk production. Our results indicate that although diets can be similar in energy content, the composition of the diet affects energy partitioning, milk production, and body composition changes.

http://dx.doi.org/10.3168/jds.2015-9467.

Comparison of the nutritional regulation of milk fat secretion and composition in cows and goats. By Toral et al., page 727\%. A comparative study with lactating cows and goats was performed to test the hypothesis that milk fat depression due to marine lipid supplements or diets containing high amounts of starch and plant oils is caused by distinct mechanisms and that each ruminant species responds differently. Results demonstrated major inter-species differences in milk fat responses to sunflower oil and starch, whereas supplements of $2 \%$ fish oil lowered milk fat content in cows and to a lesser extent in goats. Changes in milk fatty acid composition offered an insight into the possible causes for differences in mammary lipogenesis due to diet and ruminant species.

http://dx.doi.org/10.3168/jds.2015-9649.

Associations between health status and the probability of approaching a novel object or stationary human in preweaned group-housed dairy calves. By Cramer and Stanton, page 7298. The identification of sick calves can be challenging when they are housed in groups. Dairy calves were observed weekly for the first 6 wk of life for signs of illness and to determine if they approached a novel object or a stationary human. Calves with signs of bovine respiratory disease were less likely to approach both the novel object and stationary human. Additionally, calves with a fever (rectal temperature $\geq 39.4^{\circ} \mathrm{C}$ ) were also less likely to approach both the novel object and stationary human. Approach tests may represent a useful tool to aid in the identification of sick calves.

http://dx.doi.org/10.3168/jds.2015-9534.

Intestinal permeability and incidence of diarrhea in newborn calves. By Araujo et al., page 7309. Intestinal permeability is high in newborn calves for the first 24 to $36 \mathrm{~h}$ of life to allow immune passive transfer. However, permeability rapidly declines after birth to reduce the susceptibility to bacterial translocation and infection, potentially leading to diarrhea. This study shows that calves with a correct passive transfer that develop diarrhea during the first 7 to $14 \mathrm{~d}$ of life were born with impaired intestinal permeability, suggesting that they may have increased susceptibility to suffer scours. Factors modulating intestinal permeability of newborn calves need further investigation.

http://dx.doi.org/10.3168/jds.2015-9666.

Influence of ensiling, exogenous protease addition, and bacterial inoculation on fermentation profile, nitrogen fractions, and ruminal in vitro starch digestibility in rehydrated and highmoisture corn. By Ferraretto et al., page 7318. Exogenous protease addition at ensiling may increase starch digestibility in high-moisture corn. However, protease addition in dry corn or its combination with microbial inoculants in high-moisture corn to increase starch digestibility has not been evaluated. The objective of this experiment was to evaluate exogenous protease addition for effects on ruminal in vitro starch digestibility of unensiled and ensiled rehydrated corn or in combination with varied microbial inoculants in high-moisture corn. Exogenous protease addition increased ruminal in vitro starch digestibility in ensiled rehydrated corn and high-moisture corn. Microbial inoculants improved fermentation profile but not ruminal in vitro starch digestibility.

http://dx.doi.org/10.3168/jds.2015-9891.

Short communication: Effect of conjugated linoleic acid on concentrations of fat-soluble vitamins in milk of lactating ewes. By Zeitz et al., page 7328. Conjugated linoleic acids are used as feed supplements in diets for lactating ruminants due to their well-known milk fat-lowering effect; however, effects on milk concentrations of fat-soluble vitamins are unknown. We show that feeding a rumen-protected conjugated linoleic acid supplement decreased milk fat 
percentage as expected but increased milk concentrations of tocopherols and retinol when related to milk fat in early-lactating Merino ewes during a 6-wk period. http://dx.doi.org/10.3168/jds.2014-9218.

Short communication: Feeding red clover cut in the afternoon or morning to late-lactation dairy cows. By Antaya et al., page 7335. Forages cut in the afternoon (p.m.) generally yield higher concentrations of nonstructural carbohydrates $(\mathrm{NSC}=$ sugars plus starch) than those cut in the morning (a.m.). We aimed to investigate the effects of p.m.- versus a.m.-cut red clover baleage on milk yield and nutrient utilization in late lactation dairy cows. Feeding a total mixed ration containing p.m.-cut red clover baleage did not improve milk yield but decreased both milk urea-nitrogen and plasma urea-nitrogen and increased dry matter digestibility in late lactation dairy cows. No treatment effect was observed for urinary excretion of nitrogen. http://dx.doi.org/10.3168/jds.2015-9333.

Hot topic: Definition and implementation of a breeding value for feed efficiency in dairy cows. By Pryce et al., page 7340. A new breeding value that combines the amount of feed saved through improved metabolic efficiency with predicted maintenance requirements is described. The breeding value includes a genomic breeding value for residual feed intake, which is available for Holsteins only, combined with either genomic or pedigree estimated breeding values for maintenance requirements predicted using type traits. Animals that are 1 standard deviation above the mean are predicted to eat $66 \mathrm{~kg}$ (dry matter) less feed per year at the same level of milk production. The breeding value, which will be known as "feed saved," has been available for dairy farmers and breeding companies to use in their selection decisions since April 2015, when it became part of the Australian national breeding objective, the Balanced Performance Index (BPI). Selection on BPI is expected to lead to modest gains in feed efficiency.

http://dx.doi.org/10.3168/jds.2015-9621.

Bootstrap study of genome-enabled prediction reliabilities using haplotype blocks across Nordic Red cattle breeds. By Cuyabano et al., page 7351. We investigated various scenarios for genome-enabled prediction of milk production traits. The main objective was to compare the predictive ability of individual single nucleotide polymorphisms (SNP) with that of haplotype blocks, training prediction models on single or combined populations of Nordic Red cattle. After obtaining predictions, the test dataset was bootstrapped to obtain samples of prediction reliabilities, allowing statistical comparisons of the results. From training on a single breed using individual SNPs to training on a combined population using haplotype blocks, a significant gain was observed when predicting mastitis in Finnish Ayrshire and when predicting protein, fat, and milk yields in Swedish Red.

http://dx.doi.org/10.3168/jds.2015-9360.

Variances and correlations of milk production, fertility, longevity, and type traits over time in Australian Holstein cattle. By Haile-Mariam and Pryce, page 7364. Regularly monitoring genetic parameters over time is important, as changes could reduce the accuracy of genetic evaluations. This is especially true for traits such as longevity that rely on early-life predictors, as the accuracy of prediction could decrease with the change in correlations. Using a random regression approach on up to $20 \mathrm{yr}$ of data on milk yield and functional and type traits of Australian Holstein cows, we detected some changes in genetic correlations over time. When the genetic correlation of the same trait measured in different years is substantially less than 1.0 , it is likely to be due to selection or a change in trait definition.

http://dx.doi.org/10.3168/jds.2015-9537.

Short communication: Genetic relationships between functional longevity and direct health traits in Austrian Fleckvieh cattle. By Pfeiffer et al., page 7380. Disease-related losses are high in dairy cattle production. An increase of health disorders leads to early culling and decreases functional longevity. Early culling affects farm economics and animal welfare. Therefore, genetic relationships between functional longevity and direct health traits were investigated in this study. An approximate multitrait approach was applied because this approach allows the combination of information from pseudo-phenotypes derived from different statistical models. Results showed a strong genetic relationship between functional longevity and health traits and within health traits. Strict selection for healthy animals is highly recommended. http://dx.doi.org/10.3168/jds.2015-9632.

Effect of commercial hauling practices and tanker cleaning treatments on raw milk microbiological quality. By Darchuk et al., page 7384. This study focused on the effect of frequent tanker use between cleaning treatments on microbiological quality of hauled raw milk at manufacturing facilities. Three cleaning treatments were evaluated to understand if their addition could mitigate any potential negative impact. Based on this study, current hauling practices do not have any measurable effect on raw milk quality although further investigation is needed before making industry-wide recommendations.

http://dx.doi.org/10.3168/jds.2015-9746. 
Relating the carbon footprint of milk from Irish dairy farms to economic performance. By O'Brien et al., page 7394. This assessment of a nationally representative sample of grass-based dairy farms in 2012 showed that farms can improve economic performance while reducing the carbon footprint $(\mathrm{CF})$ of milk. The main measures that improved economic performance and $\mathrm{CF}$ of milk were extending the length of the grazing season and increasing milk production per hectare and per cow. However, achieving higher milk production by increasing concentrate feeding adversely affected the $\mathrm{CF}$ of milk and economic performance. Therefore, to reduce the $\mathrm{CF}$ of milk and improve economic performance, grass-based farms should aim to increase milk production per hectare from grazed grass.

http://dx.doi.org/10.3168/jds.2014-9222.
A stochastic estimate of the economic impact of oral calcium supplementation in postparturient dairy cows. By McArt and Oetzel, page 7408. The objective was to develop stochastic models that address variation in disease risks and costs in order to evaluate different simulated oral calcium supplementation strategies to multiparous postparturient dairy cows. Postpartum supplementation of cows with either a high previous lactation mature-equivalent milk yield or lameness had the highest net herd impact per 1,000 calvings at $\$ 8,313$. Postpartum supplementation of all postpartum multiparous cows with oral calcium returned a positive net herd impact approximately $80 \%$ of the time. Average milk yield at first test and immediate postpartum lameness prevalence accounted for the largest measurable variation in net herd impact. http://dx.doi.org/10.3168/jds.2015-9479. 